Revue d'histoire de l'Amérique française

REVUE D.HISTOIRE DE L'AMÉRIQUE FRANÇAISE

\title{
SOCIÉTÉ HISTORIQUE DE MONTRÉAL, Montréal, artisans, histoire, patrimoine. Montréal, Éditions Fides, 1979, 198 p. $\$ 9.95$.
}

\section{Robert Lahaise}

Volume 34, numéro 3, décembre 1980

URI : https://id.erudit.org/iderudit/303896ar

DOI : https://doi.org/10.7202/303896ar

Aller au sommaire du numéro

Éditeur(s)

Institut d'histoire de l'Amérique française

ISSN

0035-2357 (imprimé)

1492-1383 (numérique)

Découvrir la revue

Citer ce compte rendu

Lahaise, R. (1980). Compte rendu de [SOCIÉTÉ HISTORIQUE DE MONTRÉAL, Montréal, artisans, histoire, patrimoine. Montréal, Éditions Fides, 1979, 198 p. \$9.95.] Revue d'histoire de l'Amérique française, 34(3), 465-466.

https://doi.org/10.7202/303896ar d'utilisation que vous pouvez consulter en ligne.

https://apropos.erudit.org/fr/usagers/politique-dutilisation/ 


\section{NOTES BIBLIOGRAPHIQUES}

SOCIÉTÉ HISTORIQUE DE,MONTRÉAL, Montréal, artisans, histoire, patrimoine. Montréal, Éditions Fides, 1979, 198 p. \$9.95.

De 1859 à 1921, la Société historique de Montréal édita douze «livraisons» de ses Mémoires. Il s'agissait là principalement de la publication de sources utiles - Kalm, Dollier de Casson, Mère Morin, etc. de cette ère nostalgiquement à redorer que fut notre Régime français...

Cette même Société décide aujourd'hui de recommencer à publier ses Mémoires, en optant cette fois pour la présentation de brèves (parfois trois pages...) études relatives (théoriquement) à notre métropole.

Divisé en trois parties, le recueil nous offre des articles sur les «artisans, histoire, (et) patrimoine» de Montréal. Précisons immédiatement que les historiens marxistes n'en sauraient faire leur livre de chevet... et qu'on retrouve chez les "artisans», non des charpentiers ou cordonniers, mais des La Dauversière, Maisonneuve ou Viger.

[465]

RHAF, vol. 34, no 3, décembre 1980 
Quant à la deuxième partie: «quelques événements heureux ou malheureux survenus à Montréal au XIXe et au XXe siècle», on ne peut pas dire que son titre s'avère thématiquement trop contraignant. Toutefois, des articles «bien fouillés» - entre autres "La cité de Maisonneuve», "Les chevaliers de Saint-Crépin», "L'épidémie de variole en 1885», "L'affaire Guibord», etc. - nous donnent un aperçu particulièrement vivant de ces lieux ou incidents.

Enfin, dans la troisième et dernière partie, quelques récits de voyages - trop souvent nostalgiquement emphatiques, style "Québec, berceau de nos ancêtres»... - nous permettent quelques ballades à peu près partout, sauf à Montréal.

En somme, une heureuse idée que ce retour à la publication des Mémoires, mais où il faudrait sans doute, d'une part, repenser à une formule plus clairement thématique, et, d'autre part, éviter les dangers que peut représenter l'aspect beaucoup trop «vieille France» de plusieurs articles. 